Published by English Language Education Department of UMG

\title{
An Analysis Of Student's Ability In Translating Thesis Abstract At Management Department In The Faculty Of Economy University Of Muhammadiyah Gresik
}

\author{
Faricah Nabila \\ Universitas Muhammadiyah Gresik, Jawa Timur, Indonesia \\ Jl. Sumatra No. 101 GKB Gresik \\ E-mail: faricah@yahoo.com
}

Received: January 102020

Accepted: January 172020

Published: February 9,2020

Doi : http://dx.doi.org/10.30587/jetlal.v4i1.2298

\begin{abstract}
Non-English Department students in the end of the study will need to create an abstract in English. As the students who do not learn English extensively, they have difficulties in translating abstract from Indonesia to English. Therefore, in their thesis abstracts are usually found some errors. This research has an objective to find the common errors committed by the students in translating thesis abstract. In this research, there were three main steps to find the result, first, the researcher gathered the documents and listed the errors committed by the students, then compared the errors to find the common one and the last, analyzed the students translation to find the average ability of the students in translating thesis abstract. The result showed the common errors in translation were caused by the difference of language pattern of source language and target language.
\end{abstract}

Key words : translation, student ability, English language

\section{Introduction}

Translation is a process of changing the source language into a text of the target language by considering the meaning from both languages and the important thing in translating a language, the are some rules which needs to be followed (Sudarno, 2011). In the university level, students are required to make abstracts for the thesis which uses Engish and it become an important aspect for the university students to be mastered because it is the international language that support the communication with other people. Moreover, there are many supporting references in English, so the university students need to improve their ability in English. In English teaching field there are two types of English situation, they are English as Foreign Language (EFL) and English as Second Language (ESL). EFL situation is the condition where English is not the public mean of communication and in ESL situation, English is spoken in almost every place or can be understood to almost everyone.

The process of interpreting information from the source language to the target language in the written form is called translation. The text can be in the form of documents, articles, literatures, journals, instructions, etc. In this part there are aspects of translation that will be discussed, the first is the types of translation, the second is the elements of translation and the last is the errors in translation. There are three types of translation according to the language form and each type has different purpose, they are (1) literal translation; (2) faithful translation; and (3) communicative translation. Literal translation is the type of translation which translates the text based on the original text. It translates the text from word for word. The second one is faithful translation which translates the precise context of the text according to the grammatical structure. The third one is communicative translation, it translates text which focus on the social condition to make the reader easy to understand the message of the text.

Each of these translation has specific purpose, for the literal translation, it is used to translate the text that value the original meaning, but some researcher say that it is still appr opriate to add words to make the text more understandable. Then for the faithful translation, it is used to translate the text that preserves the source language, usually used to translate ancient literature to keep the ancient atmosphere for the reader. The communicative 
Published by English Language Education Department of UMG translation is used to translate popular text so it has the purpose to make an easy process of transferring information. (Newmark ,1987)

\section{Methods}

In this research, the writer will use document analysis method to answer the research questions. This method is used to describe the students' ability in translating thesis' abstract from Indonesian to English and to describe errors that were made by the students. The subjects of this research are 24 students of Management Department in Muhammadiyah University who had graduated in the year of 2015. The writer took five students, selected using random sampling method. It means that all students have the same chance to be chosen as the subjects of this study. The writer considered that 5 students of Management Department can represent the students' ability in translating thesis abstract from Indonesian to English. In this research, the researcher uses documentation coming from students' thesis especially in abstract as the instrument to collect data. The thesis abstract were collected from students' thesis in Management Department at University of Muhammadiyah Gresik who had graduated in the year of 2015. The writer analyzed it by using document analysis method. The writer will do some steps in order to find out the answers to the research questions. The analysis will be carried out through several steps. They are: (1) reading the products of students' translation in translating thesis' abstracts in order to get appropriate data of the research, (2) identifying the errors of translation, and (3) analyzing and describing the errors by classifying the types of error in translation. The procedure above was implemented as the guidance for the researcher in conducting this research. Further explanation about the steps of ADDIE model could be explained as follows.

\section{Findings}

Students' abstract were collected from Management Department in the period of 2015, the total number of the abstracts is 5, and they were gathered and randomly selected from the Department's archives. The analysis will be about the errors committed by the students in translating the abstract from Indonesian to English, then listing the errors to find out the common errors and to find out the students ability in translating thesis abstract.

The analysis was done in three steps, the first step is to analyze the errors in the students abstract and categorize the errors. Then, the second step was done by analyzing the common errors of the students' abstract, and finally, the researcher analyzed the students ability using percentage of the correct translation of the abstract.

Percentage of Students' Ability in Translating Abstract

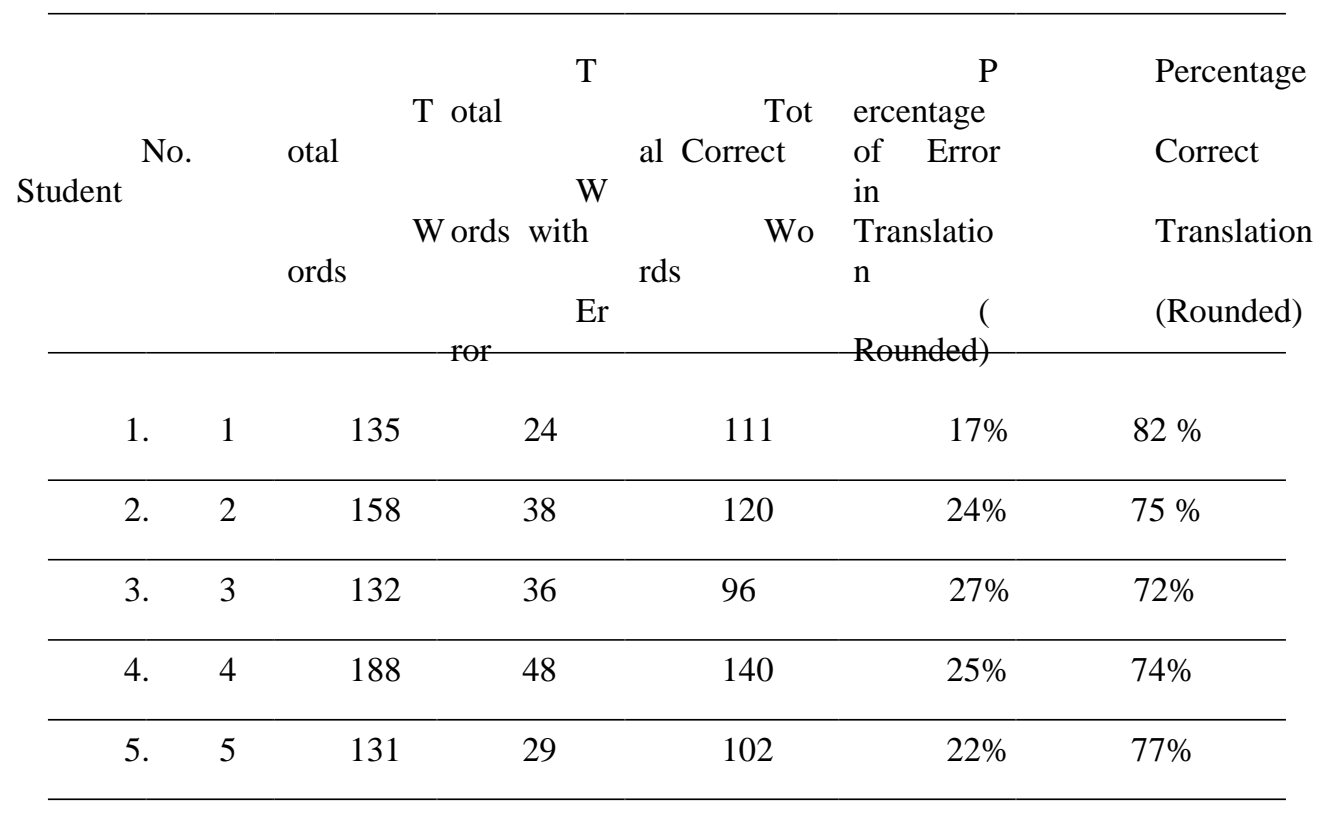


Published by English Language Education Department of UMG

Average $23 \% \quad 76 \%$

The percentage of error shows the students' error in translating abstract, the lowest percentage was achieved by student 1 with the number of $17 \%$ and the highest percentage of errors was done by student 3 , with the percentage of errors of $27 \%$. The average error from the students is $23 \%$.From the average of the correct words of the students, we can conclude that the average ability of students in translating abstract is around $76 \%$ The analysis of students' abstract translation showed the result that there are six types of errors in translation, (1) grammatical error including omission, addition, incorrect article and tenses, (2) mistranslation, (3) localization error/ misformation, (4) inappropriate use of words, (5) errors of consistency, and (6) excessive word (redundancy).

From 5 students' abstract translation, here is the table of comparison from students'

errors in translation.

Table 4. Comparison and percentage of students' error in translation

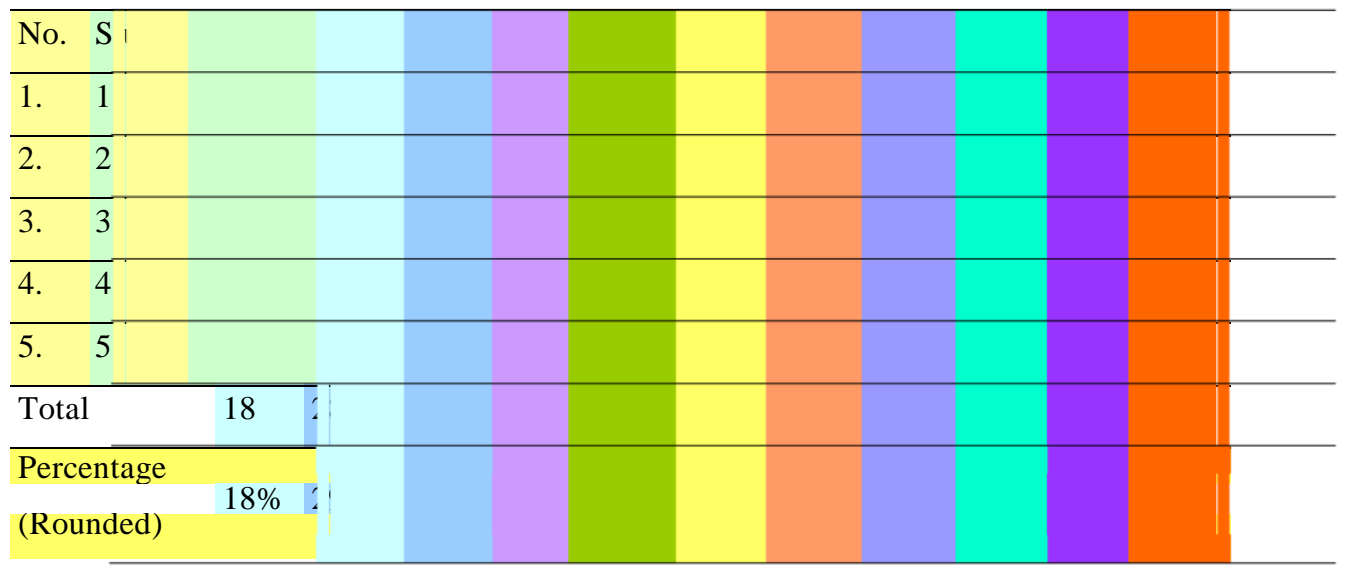

GE : Grammatical Error

OM : Omission

AD : Addition

INAR : Inappropriate Article

TNS : Tense
MST : Mistranslation
MSF : Misformation
CNS : Error of Consistency
INP : Inappropriate Use of Words
EXW : Excessive Word

The result of comparison shows that the three highest errors of translation are omission, grammatical error, and mistranslation. The errors of omission usually appear when the students do not write the subject of the sentence or the verb in the sentence, then the grammatical error 
happen because the source language and the target language have different pattern of sentence order, and the mistranslations appear because of the students incorrectly translate the words.

All of those three errors in translation apparently happen because of the different structure from source language to the target language, it is because the students' source language acts as the scaffolding to the target language (Llach, et al., 2005). So, to avoid those errors in translation, it is better for the students to learn the pattern and the basic grammar of the target language and what makes it different to the source language.

The process of instructional design ADDIE (Analysis Design Development Implementation Evaluation) has been implemented to support the Research and Development (R \& D). The final product of this study is Basic Writing module (paper-based) that was supported with Basic Writing application as learning media.

\section{Basic Writing Module}

The module covers the materials of Basic Writing course that are written based on the basic competences that have been stipulated in RPS (Rencana Pembelajaran Semester). The way to design the tasks was adjusted based on the result of students need analysis. It contains eight chapters that discuss about: 1) Simple sentence, compound sentence, and complex sentence. 2) Topic sentence, controlling idea, and supporting sentences. 3) Concluding sentence and outline. 4) Developing simple academic paragraph. 5) Review and revise expository paragraph. 6) Descriptive paragraph. 7) Recount paragraph. 8) Peer-editing. In each chapter contains seven activities. Those activities are: 1) Starting point. 2) Beyond the question marks. 3) Let"s think. 4) Share your idea. 5) Verify your opinion. 6) Compelling the principle. 7) Exercise.

The example of Basic Writing module can be seen in Figure 63. The cover of chapter 6 contains chapter title, chapter topic, GIO (General Instructional Objectives, and SIO. The chapter title is "It Looks Good". The chapter topic is "Descriptive Paragraph". The goal of learning in this chapter is written in GIO to represent the basic competence, i.e. student are able to identify characteristics of descriptive paragraph and write and develop it own. To ease the lecturer proves the goal of learning, the SIO is constructed. In this chapter, the SIO covers four indicators. Those indicators are understanding the elements of descriptive paragraph, understanding the device to make effective description, understanding the device to make effective description, understanding the way to achieve coherence in descriptive paragraph, and developing descriptive paragraphs.

The first principle of discovery learning step, stimulation, is represented by activity 1: starting point. The students are asked to read descriptive paragraphs to stimulate them about the material that they will learn. Then in activity 2: beyond the question marks as representation of problem statement step, students are given some problems to be solved about the meaning of descriptive paragraph, the elements of descriptive paragraph, the device to make effective description in descriptive paragraph, and the device to achieve coherence in descriptive paragraph. The student can do it in group. The aim of this chapter is to state the hypotheses or temporary answer or understanding towards the problems that have been asked.

To check whether or not the student hypotheses that have been made at the previous activity are right, they prove it by doing some tasks in activity 3: let's think as representation of data collection step. In group, the students are asked to analyze the elements of descriptive paragraph, the device to make effective description, and the device to achieve coherence. Individually, students are asked to write descriptive paragraph as closely as possible based on their outline. In activity 4:share your idea, as representation of data processing step, students process and interpret all of the information that has been obtained from the previous activity to get the valid result. They are asked to make group presentation and individual consultation.

Activity 5: verify your opinion represents the fifth step of discovery learning, i.e. verification. In this activity, students get explanation relates to the example of descriptive paragraph, the device to make effective description, and the example of the device to achieve coherence based on the paragraphs in activity 1 . The last activity, activity 6: compelling the principle as representation of generalization step, gives explanation to the students about the discussed material. To assess students understanding towards the discussed material, they can do some exercise in activity 7: exercise.

\section{CONCLUSION}

An analysis was done to find out the students' ability in translating abstract to know the errors in translation and the common errors in translation for the Management Department students'. When translating an abstract, we are aware that this type of text is included in Economic text, it needs specific terms in translating the source language. The findings of errors type and common errors hopefully could help the students achieve better translation by knowing the common errors in translating abstract, those particular point could be fixed in the future and anticipated when they write thesis abstract. So, the students' could decrease the errors in their translation. To do this documents analysis, there are three steps of the analysis, the first is to gather information from the students abstract thesis to make the list of errors committed by the students, then the second step is categorized each errors to know the most common errors committed by the students in translating abstract, then the third step is to analyze the students' ability by looking at the errors 
percentage of the translation. An analysis of 5 thesis abstract from the students of Management Department at University of Muhammadiyah Gresik shows that there are six types of errors in translating thesis abstract. They are: (1) grammatical error including omission, addition, incorrect article and tenses, (2) mistranslation, (3) localization error/ misformation, (4) inappropriate use of words, (5) errors of consistency, and (6) excessive word (redundancy). Throughout the analysis of students abstract translation, the average errors percentage is $23 \%$, so averagely students will have around $23 \%$ errors in their translation. From the analysis of five students abstract, the lowest percentage of errors is $17 \%$ and the highest percentage of errors is $27 \%$. Then, from the average errors of translation, we can know the students accuracy in translating their thesis abstract is around $76 \%$

\section{Conclusion}

Based on the research finding and discussion, the research conclusion can be drawn as follows. The existence of Basic Writing module that is supported by Android application is hoped to be able to be meaningful additional learning sources. Also, it is used to solve the problem that is faced by the learners in developing academic paragraph, especially in composing the supporting sentences. Basic Writing module is developed based on discovery learning principle, i.e. stimulation, problem statement, data collection, data processing, verification, and generalization. Basic Writing application that has been developed is oriented to the Android operating system. The application is easy to be operated and has features to facilitate independent learning, such as the summary of the material for each unit and exercise that are programmed with information gap and multiple choice forms. Those exercise models provide feedback relates to the userse $^{\text {ee }}$ answer. In multiple choices form, the sound effect is adjusted based on feedback notification (wrong or right answer). Also, the vibration effect is included to support the right answer. The application provides menu choice, easy operated navigation buttons, consistent user interface, attractive colour composition, and contains multimedia object, including texts, sound, and pictures that are supported to the material presentation.

The eligibility level of the product according to media expert includes in "Good" category; meanwhile, the eligibility level of the product according to material expert includes in "Very Good" category. The eligibility level of the product according to English Education Department students who enrolled in Basic Writing subject at 2015/2016 period includes in "Very Good" category.

The developed products of this study give innovative contribution in Basic Writing subject. The previous Writing module and books were developed in paper based only. In this research, the paper based module is facilitated with Android application as supplement. However, the application is only support for Android high version.

\section{References}

Blake, Gary and Bly, Robert W. 1993. The Elements of Techical Writing. New York: MacmillanPublishers.

Gamoran A, Mare RD. Secondary school tracking and educational inequality: Compensation, reinforcement, or neutrality? American Journal of Sociology. 1989;94:1146-1183.

Bhatia, Namit 1992. The Oxford Companion to the English Language. Oxford: Oxford University Press. Newmark, Peter. 1987. A Textbook of translation. Englewood Cliffs, N.J.: Prentice-Hall International. Knees, Caroline. "13 Translation Errors That Can Ruin Your Content”. June 30, 2016. http://www.nwiglobal.com/blog/13-translation-errors-that-can-ruin-your-content/

Kose, Serhan. 2011. The Effect of Form and Meaning Focused Translation Instruction to the Language Skill Levels of ELT Students.Vol, 19 no 2. Kastamonu Education Journal.

Priyono. 2005. "Lexical Constraints in Translation and Learning English as Foreign Language in Indonesia". TEFLIN Journal, Volume 16, Number 2, August 2005. Adams, P.D. (1993). Basic Writing Reconsidered. Journal of Basic Writing, 12 (1), 2 